\title{
Evaluation of tenogenic differentiation potential of selected subpopulations of human adipose-derived stem cells
}

\author{
Ana I. Gonçalves ${ }^{1,2}$ (1) | Dominika Berdecka ${ }^{1,2}$ (i) | Márcia T. Rodrigues ${ }^{1,2,3}$ | \\ Aysegul Dede Eren ${ }^{4}$ | Jan de Boer ${ }^{4}$ | Rui L. Reis ${ }^{1,2,3}$ | Manuela E. Gomes ${ }^{1,2,3}$
}

\author{
${ }^{1}$ 3B's Research Group, I3Bs - Research \\ Institute on Biomaterials, Biodegradables and \\ Biomimetics, University of Minho, \\ Headquarters of the European Institute of \\ Excellence on Tissue Engineering and \\ Regenerative Medicine, Guimarães, Portugal \\ ${ }^{2}$ ICVS/3B's-PT Government Associate \\ Laboratory, Braga, Portugal \\ ${ }^{3}$ The Discoveries Centre for Regenerative and \\ Precision Medicine, Headquarters at University \\ of Minho, Guimarães, Portugal \\ ${ }^{4}$ MERLN Institute for Technology-Inspired \\ Regenerative Medicine, Department of Cell \\ Biology-Inspired Tissue Engineering, \\ Maastricht, The Netherlands

\section{Correspondence} \\ Manuela E. Gomes, 3B's Research Group, I3Bs \\ - Research Institute on Biomaterials, \\ Biodegradables and Biomimetics, University of \\ Minho, Headquarters of the European Institute \\ of Excellence on Tissue Engineering and \\ Regenerative Medicine, AvePark, Parque de \\ Ciência e Tecnologia, Zona Industrial da \\ Gandra, 4805-017 Barco, Guimarães, Portugal. \\ Email: megomes@i3bs.uminho.pt \\ Funding information \\ H2020 Marie Skłodowska-Curie Actions, \\ Grant/Award Number: 676338; Horizon 2020 \\ Framework Programme, Grant/Award Num- \\ ber: 739572; LINK, Grant/Award Number: \\ FCL67723; European Regional Development \\ Fund, Grant/Award Number: NORTE-01- \\ 0145-FEDER-000021; FCT, Grant/Award \\ Number: PTDC/CTM-CTM/29930/2017 \\ (POCI-01-0145-FEDER-29930); European \\ Research Council CoG MagTendon, Grant/ \\ Award Number: 772817; Achilles Twinning, \\ Grant/Award Number: 810850; The Discover- \\ ies CTR; TEAMING, Grant/Award Number: \\ 739572; European Union Framework Pro- \\ gramme for Research and Innovation HORI- \\ ZON 2020, Grant/Award Number: 676338
}

\begin{abstract}
Identification of a suitable cell source and bioactive agents guiding cell differentiation towards tenogenic phenotype represents a prerequisite for advancement of cellbased therapies for tendon repair. Human adipose-derived stem cells (hASCs) are a promising, yet intrinsically heterogenous population with diversified differentiation capacities. In this work, we investigated antigenically-defined subsets of hASCs expressing markers related to tendon phenotype or associated with pluripotency that might be more prone to tenogenic differentiation, when compared to unsorted hASCs. Subpopulations positive for tenomodulin (TNMD+ hASCs) and stage specific early antigen 4 (SSEA-4+ hASCs), as well as unsorted ASCs were cultured up to 21 days in basic medium or media supplemented with TGF- $\beta 3$ (10 $\mathrm{ng} / \mathrm{ml})$, or GDF-5 (50 ng/ml). Cell response was evaluated by analysis of expression of tendon-related markers at gene level and protein level by real time RT-PCR, western blot, and immunocytochemistry. A significant upregulation of scleraxis was observed for both subpopulations and unsorted hASCs in the presence of TGF- $\beta 3$. More prominent alterations in gene expression profile in response to TGF- $\beta 3$ were observed for TNMD+ hASCs. Subpopulations evidenced an increased collagen III and TNC deposition in basal medium conditions in comparison with unsorted hASCs. In the particular case of TNMD+ hASCs, GDF-5 seems to influence more the deposition of TNC. Within hASCs populations, discrete subsets could be distinguished offering varied sensitivity to specific biochemical stimulation leading to differential expression of tenogenic components suggesting that cell subsets may have distinctive roles in the complex biological responses leading to tenogenic commitment to be further explored in cell based strategies for tendon tissues.
\end{abstract}

\section{KEYWORDS}

adipose derived stromal/stem cells, subpopulation, tenogenic differentiation, tenomodulin, transforming growth factor beta 3 


\section{I INTRODUCTION}

Tendons are specialized connective tissues that transmit forces between muscles and bones, and thus enable body motion. Tendon injuries are prevalent injuries among musculoskeletal conditions, affecting competitive and recreational athletes to the sedentary population, hence imposing a serious social and economic burden on the society. Due to low cellularity, poor vascularization, and innervation tendons possess limited intrinsic healing capacity (Sharma \& Maffulli, 2006). Clinical management of tendon injuries remains highly challenging, offering less than satisfactory long-term treatment outcomes. Though there has been an increasing interest in application of tissue engineering approaches, identification of a suitable cell source and bioactive agents guiding cell differentiation towards tenogenic phenotype, represents an obvious prerequisite for advancement of such strategies.

Several cell populations have been investigated for tendon therapy, ranging from embryonic to terminally differentiated cells (Schneider, Angele, Järvinen, \& Docheva, 2017), each with its own limitations, such as cell scarcity and donor site morbidity in the case of tenocyte isolation, or ethical and safety concerns related to the use of embryonic stem cells (ESCs; J. Thomson et al., 1998). In this context, mesenchymal stromal/stem cell (MSC) populations isolated from adult tissues may represent a more clinically relevant and preferential cell source. Particularly, adipose-derived stromal/stem cells (ASCs) offer abundance and ease of isolation by a minimally invasive procedure (Jurgens et al., 2008), while sharing several key characteristics with bone marrow-derived counterparts (Wagner et al., 2005; Zuk et al., 2001). Nevertheless, 'standard' isolation methodologies based on enzymatic digestion of adipose tissue and plastic adherence yield a highly heterogeneous population, representing a mixture of stem and progenitor cells in different stages of lineage commitment with varying differentiation capacities (Mitchell et al., 2006; Yoshimura et al., 2006; Zuk et al., 2002). Clonal analysis of human ASCs revealed that only $21 \%$ of clones were tripotent, whereas $31 \%$ and $29 \%$ were classified as bi- and unipotent, respectively (Guilak et al., 2006). Importantly, it is postulated that specific modifications in isolation procedures and culture conditions may favour selection and expansion of specific cell subsets, despite phenotypically identical starting populations. As it is increasingly recognized that the intrinsic heterogeneity of MSC preparations has its functional consequences and determines the efficacy of therapeutic applications, several studies aiming at identification of stem cell subpopulations prone to a specific lineage differentiation are being investigated (Pérez-Silos, Camacho-Morales, \& Fuentes-Mera, 2016). These approaches are usually based on selection of antigenically defined subsets, employing fluorescence activated cell sorting (FACS), or magnetic activated cell sorting (MACS). However, MSC phenotype is subjected to dynamic changes along culture time in vitro and some surface molecules recommended for MSC description (Zuk et al., 2002), such as CD105, CD90 and CD73 are also found on other cell populations, like endothelial cells, smooth muscle cells, or fibroblasts (Mitchell et al., 2006; Zuk et al., 2001). Consequently, there is an ongoing search for alternative 'stemness' markers enabling enrichment in cells that exhibit high CFU-Fs and multipotency, or even ESC-like features (Lv, Tuan, Cheung, \& Leung, 2014).

Stage specific embryonic antigen 4 (SSEA-4) is one of surface markers commonly employed to describe pluripotent cells, such as ESCs and induced pluripotent stem cells (iPSCs; Adewumi et al., 2007; Thomson, 1998). SSEA-4 is a globoseries glycolipid that was first used to delineate changes during mouse embryonic development (Shevinsky, Knowles, Damjanov, \& Solter, 1982). Prospects on a subset of cells within the human adipose tissue that expresses a SSEA-4 marker, could assume a stem cell population more likely to commit to desirable phenotypes.

Tenomodulin (TNMD) represents a type II transmembrane glycoprotein that is mainly expressed in hypovascular connective tissues, such as tendons, ligaments and skeletal muscle epimysium (Brandau, Meindl, Fässler, \& Aszódi, 2001; Shukunami, Oshima, \& Hiraki, 2001; Yamana et al., 2001). It is also found in sclera and cornea of the eye, chordae tendineae in the heart and adipose tissue (Kimura et al., 2008; Oshima, Shukunami, Honda, Nishida, \& Tashiro, 2003; Saiki et al., 2009). Although its function in vivo is not fully understood yet, genetic studies using TNMD knockout model revealed that TNMD deficient mice displayed reduced cell density and proliferation, as well as abnormally increased collagen fibril diameters in postnatal tendons (Docheva, Hunziker, Fassler, \& Brandau, 2005). Loss of TNMD expression in Tendon Stem/Progenitor Cells (TSPCs) resulted in decreased proliferation and clonogenicity, together with earlier onset of senescence in knockout TSPCs, when compared to wild type cells (Alberton et al., 2015). Interestingly, recent reports from our group and others suggest that enrichment in TNMD expressing cells (Goncalves, Gershovich, Rodrigues, Reis, \& Gomes, 2018; Hou et al., 2017), or induction of TNMD expression (Jiang et al., 2017) results in MSC populations with superior tenogenic differentiation potential.

Growth factors (GFs) represent signalling molecules potent at regulation of cell proliferation and differentiation and are commonly employed in TE strategies. Specifically, the transforming growth factor beta (TGF- $\beta$ ) superfamily plays a crucial role in tendon development and healing. Disruption of TGF- $\beta$ signalling in TGF- $\beta 2^{-/-}$and TGF- $\beta 3^{-/-}$double mutant embryos resulted in the loss of tendons and ligaments in limbs, trunk, tail and head (Pryce et al., 2009). Furthermore, TGF- $\beta 3$ is the main inducer of scleraxis, an early expressed tendon marker (Perucca Orfei et al., 2019), acting as a potential trigger of tenogenesis. TGF- $\beta 3$ has also been described to decrease tendon adhesion and promote tendon healing (Jiang et al., 2016), highlighting TFG- $\beta 3$ as a molecule of interest in tendon biology and regenerative mechanisms. Additionally, growth differentiation factors (GDFs) that constitute a subfamily of bone morphogenetic proteins (BMPs) contribute to tendon maintenance and repair. GDF 5, 6 and 7 promoted ectopic neotendon/ligament formation in rats (Wolfman et al., 1997). GDF-5 deficient mice demonstrated disrupted tail and Achilles tendon phenotype and delayed tendon healing after injury (Chhabra et al., 2003). TGF- $\beta 3$ and GDF- 5 have been shown to improve tendon healing in tendon injury models and promote tenogenic differentiation of MSCs (James, Kumbar, Laurencin, Balian, \& Chhabra, 2011; Leung, Jana, Tsao, \& Zhang, 2013; Manning et al., 2011). 
Nevertheless, to date no single factor has been identified as required and sufficient for tendon progenitor specification. It is expected that a particular balance between transcriptional regulators relevant for several mesenchymal lineages determines their tenogenic commitment. Improved understanding of the effects of single growth factors may thus facilitate a rational design of more complex arrays investigating combinatorial effects of several molecules applied simultaneously or sequentially.

In the present study it was hypothesised that antigenically-defined subpopulations of ASCs that express markers related to tendon phenotype, or usually associated with pluripotency might be more prone to differentiate towards tenogenic lineage, when compared to full, unsorted ASC fraction. It was further hypothesised that such subsets might respond more effectively to biochemical cues provided by culture media supplemented with GFs for the induction of tenogenic commitment, namely TGF- $\beta 3$ and GDF-5, as referred above. To test this hypothesis, unsorted ASCs and subpopulations positive for either TNMD or SSEA-4 were cultured up to 21 days in standard conditions (CTR) or media supplemented with TGF- $\beta 3$ (10 ng/ml), or GDF-5 (50 $\mathrm{ng} / \mathrm{ml}$ ). GF concentrations were selected on the basis of published reports. Cell response to biochemical stimulation was evaluated weekly by analysis of gene expression profile of tendon-related markers and deposition of extracellular matrix (ECM) proteins.

\section{2 | MATERIALS AND METHODS}

\section{1 | Cell isolation and subpopulation sorting}

Human liposuction aspirates were obtained from healthy females ( $n=3$ ) with an average age of 42 years, under informed consent, according to the protocols previously approved by the Ethical Committee of Hospital da Prelada (Porto, Portugal). hASCs were isolated from lipoaspirates employing enzymatic digestion, as described previously (Zhu, Heydarkhan-Hagvall, Hedrick, Benhaim, \& Zuk, 2013). Briefly, tissues were rinsed in phosphate buffered saline (PBS) and immersed in $0.05 \%(\mathrm{w} / \mathrm{v})$ collagenase type II (Sigma/C6885) solution for $1 \mathrm{hr}$ at $37^{\circ} \mathrm{C}$, under continuous agitation. The suspension was then centrifuged for $10 \mathrm{~min}$ at $800 \times g$ at $4^{\circ} \mathrm{C}$ and supernatant was discarded. Remaining pellet, identified as stromal vascular fraction (SVF), was suspended and plated in Minimum Essential Medium (a-MEM, Alfagene) supplemented with $10 \%(\mathrm{v} / \mathrm{v})$ Fetal Bovine Serum (FBS, Alfagene) and $1 \%(\mathrm{v} / \mathrm{v}$ ) antibiotic/antimycotic solution (A/A, Alfagene). Cells were incubated in a humidified atmosphere at $37^{\circ} \mathrm{C}$ with $5 \% \mathrm{CO}_{2}$ for $24 \mathrm{hr}$, and then washed extensively with PBS to remove residual erythrocytes. Culture medium was replaced every 3 days and cells were subcultured at $80 \%$ confluence.

hASCs subpopulations expressing either SSEA-4 or tenomodulin were sorted using magnetic beads (Dynabeads ${ }^{\circledR}$ M-450 Epoxy, Invitrogen) precoated with anti SSEA-4 (Santa Cruz Biotechnology, sc-59368), or anti tenomodulin (Santa Cruz Biotechnology, sc-49324) antibodies, according to the manufacturer's instructions, as described in detail elsewhere (Gonçalves, Gershovich, Rodrigues, Reis, \& Gomes,
2018). Tenomodulin is a single-pass type II membrane protein, and the deduced 317 amino acid protein contains an $\mathrm{N}$-terminal transmembrane domain. This antibody was raised against a peptide mapping within a C-terminal extracellular domain of Tenomodulin of human origin.

hASCs were subjected to the sorting procedure at passage P1 and selected cell populations were expanded in basal medium, namely aMEM supplemented with 10\% FBS and 1\% A/A. Three days after immunomagnetic sorting, TNMD+ hASCs and SSEA-4+ hASCs were fixed in $10 \%$ neutral buffered formalin (Thermo Fisher Scientific) for 20 min at room temperature (RT), washed with PBS and permeabilized with $0,1 \%$ ( $v / v$ in PBS) Triton X-100 (Sigma Aldrich) for 20 min at RT. After blocking with $1 \%(\mathrm{w} / \mathrm{v}$ in PBS) bovine serum albumin (Sigma Aldrich) for $1 \mathrm{hr}$ at RT, primary antibodies against Tenomodulin or SSEA-4 were incubated overnight at $4^{\circ} \mathrm{C}$. Cells were then washed with PBS, incubated with corresponding Alexa Fluor 488-conjugated secondary antibodies for $1 \mathrm{hr}$ at RT and counterstained with $4^{\prime}, 6$ diamidino-2-phenylindole (DAPI, Sigma Aldrich, D9542, $1 \mu \mathrm{g} / \mathrm{ml}$ in PBS). All samples were visualized using a fluorescent microscope (Axio Imager Z1m, Zeiss) equipped with a digital camera (AxioCam MRm3).

\subsection{Induction of tenogenic differentiation by biochemical stimulation}

To evaluate susceptibility of studied hASCs populations to tenogenic differentiation, unsorted hASCs fraction, SSEA-4 positive subpopulation (SSEA-4+ hASCs) and tenomodulin positive subpopulation (TNMD+ hASCs) were subjected to long-term culture in media supplemented with GFs. On the basis of previously published reports and own preliminary data, TGF- $\beta 3$ and GDF- 5 in concentrations of $10 \mathrm{ng} / \mathrm{ml}$ and $50 \mathrm{ng} / \mathrm{ml}$ respectively, were chosen for the present study. For every cell population under investigation, cells in passage P3 were seeded in 24-well plates at a density of $10^{3} \mathrm{cells} / \mathrm{cm}^{2}$. Differentiation media were composed of a-MEM supplemented with $10 \%$ FBS, 1\% A/A (basal medium), 2 mM L-glutamine (STEMCELL ${ }^{\text {TM }}$ Technologies), $0.2 \mathrm{mM}$ ascorbic acid (Wako) and TGF- $\beta 3$ (Peprotech, 10036E) or GDF-5 (Abcam, ab55329). Ascorbic acid was included in the media to promote collagen synthesis (Barnes, 1975). Basal culture medium without GFs was considered control condition (CTR). Media compositions are summarized in Table 1 . Cell response to biochemical stimulation was evaluated weekly up to 21 days by analysis of expression of tendon-associated markers on gene level and protein level, by real time PCR, immunocytochemistry and western blotting. Three independent experiments were carried out.

TABLE 1 Culture media composition used in the study

\begin{tabular}{ll} 
Medium & Composition \\
\hline CTR & Basic medium: aMEM + 10\% FBS + 1\% A/A \\
\hline TGF- $\beta 3$ & $\begin{array}{r}\text { Basic medium + } 2 \mathrm{mM} \text { L-glutamine + } 0.2 \mathrm{mM} \text { ascorbic } \\
\text { acid + TGF- } \beta 3(10 \mathrm{ng} / \mathrm{ml})\end{array}$ \\
GDF-5 & $\begin{array}{c}\text { Basic medium + } 2 \mathrm{mM} \mathrm{L-glutamine} \mathrm{+} \\
\text { acid + GDF-5 }(50 \mathrm{ng} / \mathrm{ml})\end{array}$
\end{tabular}




\section{3 | Metabolic activity and proliferation}

The cellular metabolic activity was evaluated by MTS assay (Cell Titer 96® Aqueous Solution Cell Proliferation Assay, Promega). Cells were rinsed in PBS before being $3 \mathrm{hr}$ incubated in a mixture of FBS-free and phenol red free medium and MTS solution (5:1 ratio) at $37^{\circ} \mathrm{C}$ and $5 \% \mathrm{CO}_{2}$ atmosphere. Then, $100 \mathrm{ml}$ of each sample was transferred to a new 96-well plate and the absorbance read at $490 \mathrm{~nm}$ (Synergy $\mathrm{HT}$, Bio-TeK Instruments). Triplicates were made of each sample and a blank reading was performed. Cell proliferation was assessed by Quant-iT PicoGreen dsDNA Assay Kit (P7589, Invitrogen). Samples were collected into microtubes with $1 \mathrm{ml}$ of ultrapure water and stored at $-80^{\circ} \mathrm{C}$. Then, samples were thawed, sonicated (VCX-130PB-220, Sonics) and analyzed using a microplate reader with an excitation of $485 / 20 \mathrm{~nm}$ and an emission of 528/20 nm. Samples and standards were made in triplicate.

\section{4 | RNA extraction, reverse transcription and real time RT-PCR}

To analyze gene expression, total RNA was isolated using TRI Reagent ${ }^{\circledR}$ (Sigma Aldrich) according to the manufacturer's instructions. RNA concentration and purity were determined spectrophotometrically using NanoDrop ND-1000 (Thermo Fisher Scientific). $500 \mathrm{ng}$ of total RNA were reversely transcribed using qScript ${ }^{\mathrm{TM}} \mathrm{cDNA}$ Synthesis Kit (Quanta Biosciences), following manufacturer's protocol. Primers were designed using Primer-BLAST tool and are summarized in Table 2. Real-time quantitative polymerase chain reaction (PCR) was performed on Mastercycler ${ }^{\circledR}$ ep realplex instrument (Eppendorf), employing PerfeCTA ${ }^{\circledR}$ SYBR Green FastMix (Quanta Biosciences), according to manufacturer's instructions. $5 \mathrm{ng}$ of cDNA was used per single reaction. After an initial denaturation step for $2 \mathrm{~min}$ at $95^{\circ} \mathrm{C}$, conditions for cycling comprised $10 \mathrm{~s}$ at $95^{\circ} \mathrm{C}, 30 \mathrm{~s}$ at $57-60^{\circ} \mathrm{C}$ (annealing) and $20 \mathrm{~s}$ at $72^{\circ} \mathrm{C}$. The fluorescence signal was measured after the extension step at $72^{\circ} \mathrm{C}$ and melting curves were generated at the end of the cycling to verify specificity of PCR products. $2^{-C t}$ method (Livak \& Schmittgen, 2001) was employed to evaluate relative gene expression and glyceraldehyde-3-phosphate dehydrogenase (GAPDH) served as reference gene. All values were first normalized to GAPDH, and then to CTR medium condition in unsorted hASCs at 7 days. Samples were collected and analyzed in triplicates.

\section{5 | Immunocytochemistry}

To evaluate expression of tendon-related ECM components, immunocytochemical analysis was performed. Cells were seeded on coverslips in a 24-well plate at a density of $1 \times 10^{3}$ cells $/ \mathrm{cm}^{2}$. After respective time in culture, cells were fixed with $10 \%$ neutral buffered formalin (Thermo Fisher Scientific) for $20 \mathrm{~min}$ at room temperature (RT), washed three times with PBS and permeabilized with $0.1 \%(\mathrm{v} / \mathrm{v}$ in PBS) Triton X-100 (Sigma Aldrich) for 20 min at RT. After blocking with $1 \%$ (w/v in PBS) bovine serum albumin (Sigma Aldrich) for $1 \mathrm{hr}$ at RT, primary antibodies against collagen type I (Abcam, ab90395, 1:500), collagen type III (Abcam, ab7778, 1:100) and tenascin C (Abcam, ab6393, 1:3000) were applied overnight at $4^{\circ} \mathrm{C}$. Cells were then washed with PBS, incubated with corresponding rabbit anti-mouse (Life Technologies, A11059, 1:100), or donkey anti-rabbit (Life Technologies, A21206, 1:100) Alexa Fluor 488-conjugated secondary antibodies for $1 \mathrm{hr}$ at RT and counterstained with 4',6-diamidino-2phenylindole (Sigma Aldrich, D9542, $1 \mathrm{\mu g} / \mathrm{ml}$ in PBS). To exclude nonspecific binding of secondary antibodies, negative controls omitting primary antibodies were employed. All samples were visualized using a fluorescent microscope (Axio Imager Z1m, Zeiss) equipped with a digital camera (AxioCam MRm3). Semi-quantification of immunocytochemistry was performed using ImageJ software, based on Area fraction measurement of positively stained area. Images $(n=5)$ were first thresholded to correct the signal from the background using Huang correction method.

TABLE 2 Primers used for real time RT-PCR

\begin{tabular}{|c|c|c|c|c|}
\hline Target & NCBI reference & Primers & Sequence $5^{\prime}-3^{\prime}$ & Product length (bp) \\
\hline \multirow[t]{2}{*}{ COL1A1 } & \multirow[t]{2}{*}{ NM_000088.3 } & Forward & GCCAAGACGAAGACATCCCA & \multirow[t]{2}{*}{156} \\
\hline & & Reverse & GGCAGTTCTTGGTCTCGTCA & \\
\hline \multirow[t]{2}{*}{ COL3A1 } & \multirow[t]{2}{*}{ NM_000090.3 } & Forward & CCTGAAGCTGATGGGGTCAA & \multirow[t]{2}{*}{98} \\
\hline & & Reverse & CAGTGTGTTTCGTGCAACCAT & \\
\hline \multirow[t]{2}{*}{$D C N$} & \multirow[t]{2}{*}{ NM_001920.4 } & Forward & CACAAGTTTCCTGGGCTGGA & \multirow[t]{2}{*}{154} \\
\hline & & Reverse & AGATGGCATTGACAGCGGAA & \\
\hline \multirow[t]{2}{*}{ GAPDH } & \multirow[t]{2}{*}{ NM_002046.5 } & Forward & GATTTGGTCGTATTGGGCGC & \multirow[t]{2}{*}{169} \\
\hline & & Reverse & TTCCCGTTCTCAGCCTTGAC & \\
\hline \multirow[t]{2}{*}{ SCX } & \multirow[t]{2}{*}{ NM_001080514.2 } & Forward & CAGACGGACGTACAGACAGG & \multirow[t]{2}{*}{85} \\
\hline & & Reverse & CAGCGCAGAAAGTTCCAGTG & \\
\hline \multirow[t]{2}{*}{ TNC } & \multirow[t]{2}{*}{ NM_002160.3 } & Forward & ACTGCCAAGTTCACAACAGACC & \multirow[t]{2}{*}{164} \\
\hline & & Reverse & CCCACAATGACTTCCTTGACTG & \\
\hline \multirow[t]{2}{*}{ TNMD } & \multirow[t]{2}{*}{ NM_022144.2 } & Forward & CCGCGTCTGTGAACCTTTAC & \multirow[t]{2}{*}{100} \\
\hline & & Reverse & CACCCACCAGTTACAAGGCA & \\
\hline
\end{tabular}




\section{6 | Western blotting assay}

Total cell lysates were prepared using RIPA buffer (Sigma Aldrich) supplemented with protease inhibitor cocktail (Sigma Aldrich). Samples were centrifuged for $15 \mathrm{~min}$ at $14000 \mathrm{rpm}$ at $4^{\circ} \mathrm{C}$ and clear supernatants were collected. Total protein concentration was determined using Pierce ${ }^{\mathrm{TM}}$ BCA protein assay kit (Thermo Fisher Scientific), according to the manufacturer's protocol. Forty micrograms of protein extracts were resolved in 4-15\% Mini-PROTEAN ${ }^{\circledR}$ TGX Stain-Free ${ }^{\mathrm{TM}}$ Protein Gels (Bio-Rad), followed by semi-dry transfer to Trans-Blot ${ }^{\circledR}$ Turbo $^{\mathrm{TM}}$ Mini PVDF membranes (Bio-Rad), using Trans-Blot ${ }^{\circledR}$ Turbo ${ }^{\mathrm{TM}}$ Transfer System (Bio-Rad). Membranes were blocked with 5\% nonfat milk in Tris buffered saline with Tween 20 (TBS-T) and incubated with rabbit anti scleraxis (Abcam, ab58655, 1:1000), or mouse anti beta actin (Sigma Aldrich, A2228, 1:2000) antibodies overnight at $4^{\circ}$ C. Membranes were washed three times with TBS-T and secondary anti rabbit IgG (Bio-Rad, 1706515, 1:2000) or anti mouse IgG (BioRad, 1706515, 1:4000) antibodies conjugated with horseradish peroxidase were applied for $1 \mathrm{hr}$ at RT. Visualization of the immunoreactivity was performed using Clarity $^{\mathrm{TM}}$ Western ECL Substrate (Bio-Rad, 1705060).

\section{7 | Statistical analysis}

Data are presented as mean \pm standard deviation (SD) of three independent experiments, each performed in triplicates. Statistical analysis was performed using GraphPad Prism 6 software. Two-way analysis of variance (ANOVA), followed by Tukey's multiple comparison post-test was employed to compare experimental groups. Values of $p<.05$ were considered as statistically significant.

\section{3 | RESULTS}

Human ASCs were isolated from lipoaspirates and subpopulations expressing either TNMD (TNMD+ hASCs) or SSEA-4 (SSEA-4+ hASCs) were successfully sorted using immunomagnetic beads preconjugated with specific antibodies against the antigens of interest (Figure 1).

No significant differences in metabolic activity or proliferation rate were observed between unsorted hASCs and selected subpopulations, indicating that sorting procedure employed for TNMD+ and SSEA-4+ cells isolation did not affect cell viability (Figure 2). These observations were in accordance with our previous studies, where this sorting strategy was effectively utilized (Gonçalves et al., 2018; Rada, Gomes, \& Reis, 2011). The metabolic activity and proliferation increase with time in culture $(p<.05)$ in all cell populations. Moreover, SSEA-4+ hASCs are more proliferative in TGF- $\beta 3$ supplemented medium at 14 and 21 days than in medium supplemented in GDF-5 or in basal medium $(p<.01)$.

To evaluate susceptibility of studied hASCs populations to tenogenic differentiation, unsorted hASCs fraction, SSEA-4+ hASCs and TNMD+ hASCs were subjected to long-term culture in the presence of TGF- $\beta 3$ or GDF-5. Unsupplemented culture medium (CTR) served as control culture condition.

\subsection{Gene and protein expression analysis of tendon related markers}

In order to determine the propensity of selected hASCs populations to commit towards tendon-like phenotype, gene expression levels of tendon associated markers were studied using real time RT-PCR.

It was demonstrated that treatment with TGF- $\beta 3$ resulted in significant up-regulation of expression of transcription factor scleraxis (SCX) in every cell population under investigation (Figure 3). A statistically significant increase (over 8-fold change) in the transcript levels of SCX was observed after 14 days of culture in medium supplemented with TGF- $\beta 3$, in comparison with basal medium condition $\left({ }^{* * *} p<.001\right)$ and with medium supplemented with GDF-5 $\left({ }^{* * * *} p<.0001\right)$. The highest up-regulation (11-fold change) of SCX expression was observed for TNMD-positive subpopulation at day 14 in culture supplemented with TGF- $\beta 3\left({ }^{* * * *} p<.0001\right.$ in comparison with control medium and with GDF-5 supplementation). At 21 days, SCX expression decreases in unsorted hASCs and SSEA-4+ hASCs supplemented with TGF- $\beta 3\left(^{* *} p<.01\right.$ and ${ }^{* * *} p<.001$, respectively) in comparison with the levels detected at day 14. However, in TNMD+ hASCs, SCX expression levels remained significantly higher in TGF- $\beta 3$ cultures, when compared to basic control medium $\left(^{* * *} p<.001\right.$ at day $14,{ }^{* *} p<.01$ at day 21$)$ and to medium with GDF-5 $\left({ }^{* * * *} p<.0001\right.$ at day $14,{ }^{* * *} p<.001$ at day 21 ), and to the other cell populations (${ }^{a} p<.01$ and ${ }^{b} p<.01$, unsorted hASCs and SSEA-4+ hASCs respectively, both at day 21)

The TNMD expression was increased in TNMD+ subpopulation after 21 days in culture with TGF- $\beta 3$ in comparison with basal control medium $\left({ }^{*} p<.05\right)$ and GDF-5 supplemented medium $\left({ }^{* *} p<.01\right)$ despite the fact that no statistical distinctions were found between cell groups ( $p>.05$ ) with regard to the expression of this gene (Figure 3 ).

The upregulation of scleraxis mRNA levels in response to supplementation with TGF- $\beta 3$ was further validated by protein expression analysis (Figure 4).

Western blot confirmed the presence of scleraxis in all hASCs populations after 14 days in culture. Moreover, scleraxis was increased in the presence of TGF- $\beta 3$, when compared to control medium and cultures supplemented with GDF-5.

Considering the critical role of ECM composition and organization for tendon phenotype and function, gene expression of major structural components (Figure 5a) and proteins involved in regulation of collagen fibril assembly (Figure $5 b$ ) were further investigated.

The expression of COL1A1 is low for both unsorted hASCs and subpopulations and tends to decrease with the time in culture being close to baseline levels after 21 days regardless of cell media or cell populations (Figure 5a). An 8-fold increase is observed in COL3A1 levels of the unsorted population cultured in basal and GDF-5 supplemented medium at day 14 relative to control conditions. In the presence of TGF- $\beta 3$ there is an 18 -fold increment in comparison with control values. At 14 days, the transcript levels of COL3A1 are also increased in SSEA- 
$4+$ hASCs over control conditions in basal medium and media supplemented with TGF- $\beta 3$ and GDF- 5 by 10 -fold, 17 -fold and 16- fold change, respectively. After 21 days in culture the COL3A1 levels of SSEA-4+ hASCs are lower than the ones found for unsorted hASCs.

Interestingly, TNMD+ hASCs evidence the lowest COL3A1 levels of all cell populations studied, barely reaching the 2 -fold increase over baseline after 14 days in culture. The expression is lower in respect to the unsorted hASCs independently of the culture media and to SSEA$4+$ hASCs population supplemented with both growth factors: TGF- $\beta 3$ and GDF-5 ( $p>$.05; Figure 5a).

The expression of $D C N$ is up-regulated in all cell populations, with the higher transcript values detected in SSEA-4+ hASCs (14-fold change in TGF- $\beta 3$ supplemented medium by 14 days in culture in comparison with control conditions). Moreover, TNMD+ hASCs show the lowest fold change in comparison with the other cell populations (Figure 5b). As for COL3A1 transcripts, DCN expression is decreased in medium supplemented with TGF- $\beta 3$ in comparison with basal medium (CTR; ${ }^{* *} p<.01$ day 14 and day 21 ) and to GDF-5 medium $\left({ }^{*} p<.05\right.$ day 21$)$.

A 4-fold increment in TNC expression is observed in unsorted hASCs cultured in basal medium and in SSEA-4+ hASCs cultured in basal medium and GDF-5 supplemented medium in comparison with baseline controls. Additionally, the genetic expression of TNC is low in hASCs populations stimulated with TGF- $\beta 3$ at both day 14 and 21 $(\sim 1.5$-fold increment to unsorted hASCs at day $7, p>.05)$. In TNMD + cells the highest values of TNC are detected in basal culture conditions (2-fold change to baseline values, $p>.05$ ).

\subsection{Evaluation of ECM deposition}

The expression of tendon structural proteins was further evaluated on the protein level. To characterize the matrix synthesized by selected hASC populations under different culture conditions, the deposition of collagen type I (COL1), collagen type III (COL3) and tenascin C (TNC) was investigated by immunocytochemistry (Figure 6).

Protein quantification was assessed at day 21 for all conditions studied. Collagen type I is highly detected in the different cell populations apart from the culture media conditions.

Unlike COL1, the deposition of COL3 varies with cell population and culture media. In unsorted hASCs COL3 is almost residual, independently of the culture conditions with a slight increase $(p>.05)$ with the supplementation of TGF- $\beta 3$. In the case of SSEA-4+ hASCs, the COL3 levels are high only in basal culture medium $\left({ }^{* *} p<.01\right)$. Both hASCs subpopulations evidence increased production of COL3 relative to unsorted hASCs $\left({ }^{* *} p<.01\right)$. In particular, TNMD+ hASCs shows the highest values of COL3 independently of the culture medium (in comparison with unsorted hASCs and to SSEA-4+ hASCs cultured in growth factor supplemented media, $p<.05$ ).

Although TGF- $\beta 3$ and GDF- 5 seem not to play an incremental role in COL1 and COL3 production by hASCs populations, these growth factors improve the production of TNC in the unsorted hASCs $(p<.05)$, with particular effect on TGF- $\beta 3$ cultures. However, the deposition of TNC by SSEA-4+ hASCs is decreased in growth factor supplemented medium (in relation to basal medium conditions, $p<.05)$. Interestingly, TNMD+ subpopulation shows dissimilar responses to TGF- $\beta 3$ and GDF- 5 . In TGF- $\beta 3$ cultures the TNC is lower than in basal medium while the stimulation of GDF-5 increases the production of this protein.

Overall, GFs seem to play a role in the synthesis and deposition of ECM molecules present in tendon tissues, stimulating the hASCs subsets in different ways.

\section{4 | DISCUSSION}

Adipose-derived stromal/stem cells represent a highly promising cell source for tissue engineering and regenerative medicine approaches that is currently being studied for a broad range of applications (Frese, Dijkman, \& Hoerstrup, 2016; Gimble, Bunnell, \& Guilak, 2012), including tendon engineering and regeneration (De Mattos Carvalho et al., 2011; James et al., 2011; Uysal, Tobita, Hyakusoku, \& Mizuno, 2012). Nonetheless, adipose and mesenchymal stem cell preparations in general, are burdened with high intrinsic heterogeneity, what hampers the comparison of data obtained by different labs and hinders translation of MSC-based therapies into the clinic. Indeed, MSC variability may be described at multiple levels, namely between donors, tissue sources, clonal subpopulations and single cells, as excellently reviewed by McLeod and Mauck (McLeod \& Mauck, 2017). Moreover, further variations emerge as the result of applied culture conditions, affecting both phenotype and functional differentiation potential of cells expanded in vitro. In this context, a lot of research effort has been directed at establishing strategies for the better characterization and standardization of isolation and culture protocols of MSCs to assure safety of cell therapies and speed up the progress of the field from bench to bedside. Particularly, the idea of selection of antigenically defined subpopulations of stem cells sorted on the basis of expression of specific surface molecules, has gained much attention in the past years (Johal, Lees, \& Reid, 2015; Mo, Wang, Zhou, Li, \& Wu, 2016). Remarkably, mobilized peripheral blood CD34+ progenitors have been already employed clinically for the prevention of graft-versus-hostdisease in HLA-mismatched recipients (Handgretinger et al., 2001) and for the treatment of refractory angina (Henry et al., 2016). Furthermore, several preclinical studies reported utility of MSC subpopulations for various orthopaedic applications, for instance, CD105depleted ASCs demonstrated enhanced osteogenic differentiation, whereas CD271+ cells from synovial membrane improved cartilage repair (Pérez-Silos et al., 2016).

Following this concept, we assessed the response of SSEA-4positive and TNMD-positive subpopulations in comparison with unsorted hASCs cultured up to 21 days either in basic medium or media supplemented with TGF- $\beta 3$ or GDF-5.

The cell subpopulations were successfully sorted from the crude population. We selected extra/pericellular domains for antibody bonding avoiding permeabilization of the cell membrane or other invasive methodologies, which may cause membrane rupture and release of cell content to enable viable cells and not to perturb cell responses as 
much as possible. Moreover, intracellular molecules are typically more immature and consequently may differ from the molecules expressed at the surface or extracellularly in terms of protein functionality and recognition. Thus, we investigated surface proteins previously assessed by our group (Goncalves et al., 2018; Mihaila et al., 2013).

As expected, cell metabolic activity increases along the time in culture in all conditions studied. Our data also show that cell proliferation increases from 7 to 14 days in culture and that SSEA-4+ hASC proliferation is stimulated by the TGF- $\beta 3$ supplementation in comparison with GDF-5 and to control conditions after 14 days in culture. Despite that no studies have reported on the susceptibility of SSEA-4+ cells to TGF- $\beta 3$, it is known that the TGF- $\beta$ superfamily plays crucial roles in cell processes including cell proliferation (Hao, Varshney, \& Wang, 2008). Between 14 and 21 days in culture, no significant differences were observed in the proliferation and metabolic activity of the different cell populations, which may be related to cell confluency.

In order to evaluate the capability of selected hASCs populations to tenogenic commitment, we then investigated the expression of a panel of tendon-related markers on both gene level and protein level, bearing in mind that none of them is expressed exclusively in tendon tissue (Taylor et al., 2009).

In our study, the gene expression was normalized to the keeper GAPDH. Although comparative reports have suggested other reference genes in osteogenic and cartilage differentiation studies, there is a lack of comparative reports on the most suitable reference genes for the reproducibility analysis of tenogenic markers by hASCs. Thus, following previous published studies performed by us (Gonçalves et al., 2013, Mihaila et al., 2014, Goncalves et al., 2018) and by others (Bi et al., 2007), GAPDH was selected as genetic reference. To allow direct comparison between sorted and unsorted cells, gene expression levels were expressed relative to control conditions at day 7 in unsorted hASCs.

We first focused on the expression of scleraxis and tenomodulin that are considered, respectively, early and late markers of tenogenic lineage. Scleraxis is a basic helix-loop-helix transcription factor and to date the best studied early marker of tendon progenitor cells. During embryonic development, it is first detected in the developing limb buds and in syndetome, and its expression is maintained at later stages of tendon formation up to fully differentiated cells (Cserjesi et al., 1995). Consistent with the previous findings identifying TGF- $\beta$ signalling as a potent inducer of SCX expression, critical for tendon progenitor maintenance (Pryce et al., 2009), a significant up-regulation of SCX was demonstrated for all cell populations cultured for 14 days in the presence of TGF- $\beta 3$ in our study $(p<.05)$. SCX expression decreases from 14 to 21 days in culture in unsorted hASCs and SSEA-4+ hASCs $(p<.05)$, which is expected since SCX is considered to be an early tendon marker. The incremental response of scleraxis expression to TGF- $\beta$ has been suggested to be mediated by the canonical Smad signaling pathway (Czubryt, 2012). Moreover, TGF- $\beta 3$ as inducer of scleraxis (Perucca Orfei et al., 2019), acts as a potential biomolecular trigger of tenogenesis and can inhibit later markers (Perucca Orfei et al., 2019).

Interestingly, the expression of TNMD showed basal levels in all cell populations, including in the TNMD+ hASCs. Although Liu et al. showed that ectopic SCX expression alone was not sufficient to trigger TNMD expression in murine MSCs (Liu et al., 2014), the TNMD expression in our study may be influenced by the up-regulation of SCX, a likely regulator of the TNMD gene. Qi J et al. (Qi et al., 2012) reported that knockdown of TNMD increased the expression of both scleraxis and myostatin in tenocytes, indicating a potential negative feedback loop between TNMD and its regulators.

Considering that tendons are composed mainly of extracellular matrix arranged in a complex hierarchical manner, we then focused on the expression patterns of critical structural components and molecules controlling their spatiotemporal assembly. In particular, collagen type I represents approximately $95 \%$ of the total collagen content and around $60 \%$ of tissue dry mass (Wang, 2006). Collagen type III is in turn expressed early in tendon development, playing a role in initial fibril assembly and control of fibril diameters, while its expression in mature tendon is restricted to endotenon and epitenon (Wang, 2006).

COL1A1 and COL3A1 transcript levels were slightly decreased after 14 days of culture of TNMD+ hASCs supplemented with TGF- $\beta 3$. However, in the case of unsorted cells and SSEA-4+ hASCs these levels remained stable between different conditions and with time.

In our study, COL1A1 transcripts tend to decrease to baseline levels in all cell populations with the time in culture. Although the

\section{SSEA-4+ hASCs}

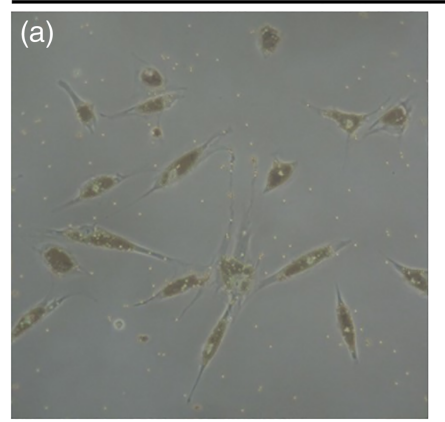

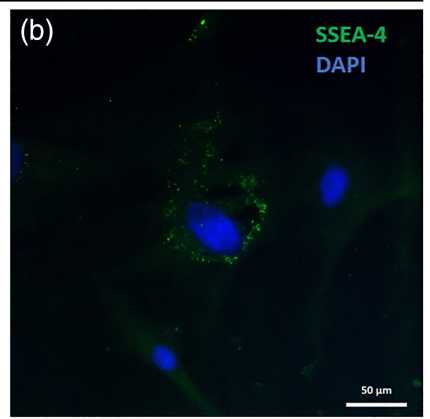

\section{TNMD+ hASCs}

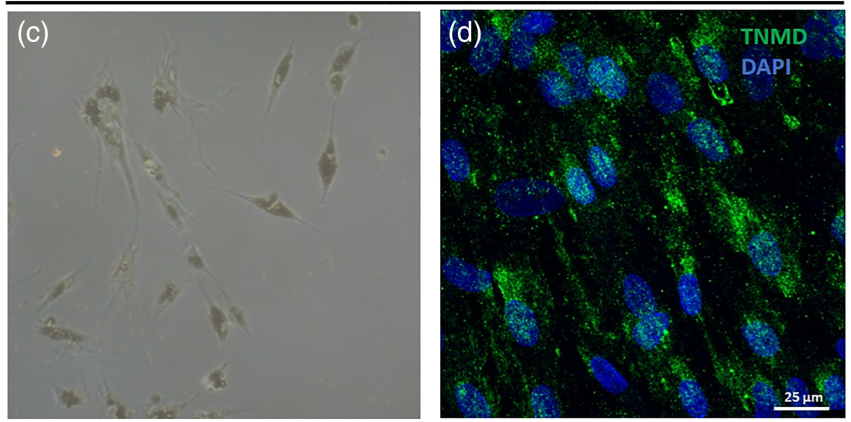

FIGURE 1 Micrographs of SSEA-4+ hASCs (a) and TNMD+ hASCs (b) 3 days after sorting on Dynabeads ${ }^{\circledR}$ M-450 Epoxy, 10x magnification. SSEA-4 (c) and TNMD (d) immunostaining (green) in SSEA-4+ and TNMD+ hASCs, respectively, 3 days after sorting. Nuclei are stained with DAPI (blue) 


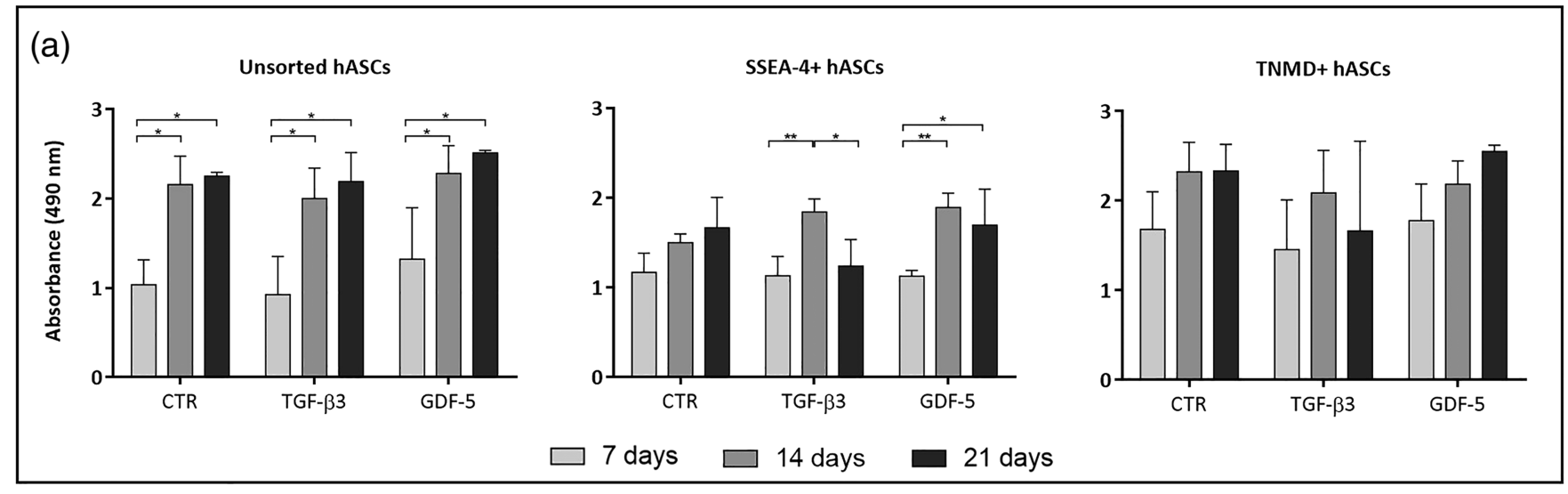

(b)
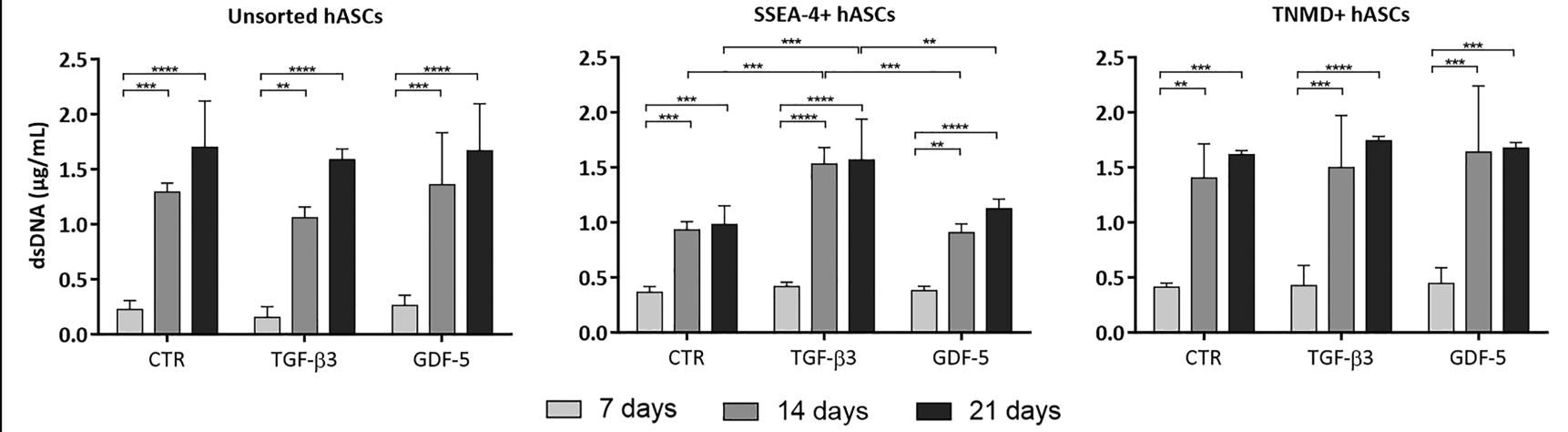

FIGURE 2 Unsorted, SSEA-4+ and TNMD+ hASCs metabolic activity (a) and proliferation (b) analysis, cultured for up to 21 days in aMEM basal medium, TGF- $\beta 3$ and GDF-5 supplemented medium conditions. Symbol ${ }^{*},{ }^{* *},{ }^{* * *}$ and ${ }^{* * * *}$ denotes study groups with statistical significant difference: $p<.05, p<.01, p<.001$ and $p<.0001$ respectively

expression of COL3A1 also decreases, the COL3A1 levels are considerable higher than those of COL1A1 at 14 days. Collagen III expression decreases gradually during development and increases after injury likely contributing to the matrix remodeling during the healing process. The high levels of COL3A1 by 14 days in comparison with control conditions suggests that collagen III could be participating in the in vitro fibrilogenesis of hASCs populations. As the fibrilogenesis occurs collagen III decreases, which is verified after 21 days in culture.

Decorin represents a prototype small leucine-rich proteoglycan (SLRP) displaying critical instructive roles in matrix assembly and signal transduction, due to its multivalent binding abilities (Chen \& Birk, 2013). It is a key modulator of collagen fibrilogenesis, capable of inhibiting lateral growth of collagen fibrils. In our study, unlike COL1A1 and COL3A1, DCN expression is not influenced by the time in culture, keeping expression levels high in unsorted hASCs and hASCs subpopulations. Decorin is high throughout development (Connizzo, Yannascoli, \& Soslowsky, 2013) and its up-regulation in our study assists the synthesis of a tendon-like ECM. Decorin-based therapies have been investigated both as a target for antisense gene therapy to improve ligament healing by manipulation of early scar functional properties (Nakamura et al., 2000) and for suppressing fibrosis, motivated by its interference with TGF- $\beta$ signalling (Schaefer \& Schaefer, 2010).

Tenascin $\mathrm{C}$ is a glycoprotein expressed in several tissues subjected to high tensile stress and it is involved in modulation of cell-matrix interactions. It is expressed during tendon embryonic development, whereas its expression in mature tissue is generally low (Burk et al., 2014; Taylor et al., 2009) and transiently elevated in response to tissue injury, when TNC mediates inflammatory and fibrotic processes (Chiquet-Ehrismann \& Tucker, 2004). Moreover, Tenascin C is significantly regulated by the tissue microenvironment and is required when active tissue modeling during embryogenesis or re-modeling after injury occurs (Brellier, Tucker, \& Chiquet-Ehrismann, 2009).

The up-regulation of TNC in SSEA-4+ hASCs cultured in basal medium and GDF- 5 supplemented medium and the lower expression of TNC in hASCs populations stimulated with TGF- $\beta 3$ suggests that the biochemical stimuli provided by growth factors investigated may contribute differently to hASCs populations with distinctive phenotypic profiles. Accordingly, the expression of COL3A1, DCN and TNC transcripts tended to decreased in TNMD+ hASCs in response to TGF- $\beta 3$.

The data reflecting relative mRNA transcript levels was then confronted with the analysis of protein synthesis and organization of deposited matrix. Immunocytochemistry analysis revealed the deposition of a rich collagenous matrix in all culture conditions with the course of experiment. Being a protein with constitutive expression in MSCs and a crucial role in ECM formation and quality, Collagen 1 was detected quite abundantly and quantified in all culture conditions and cell populations. 

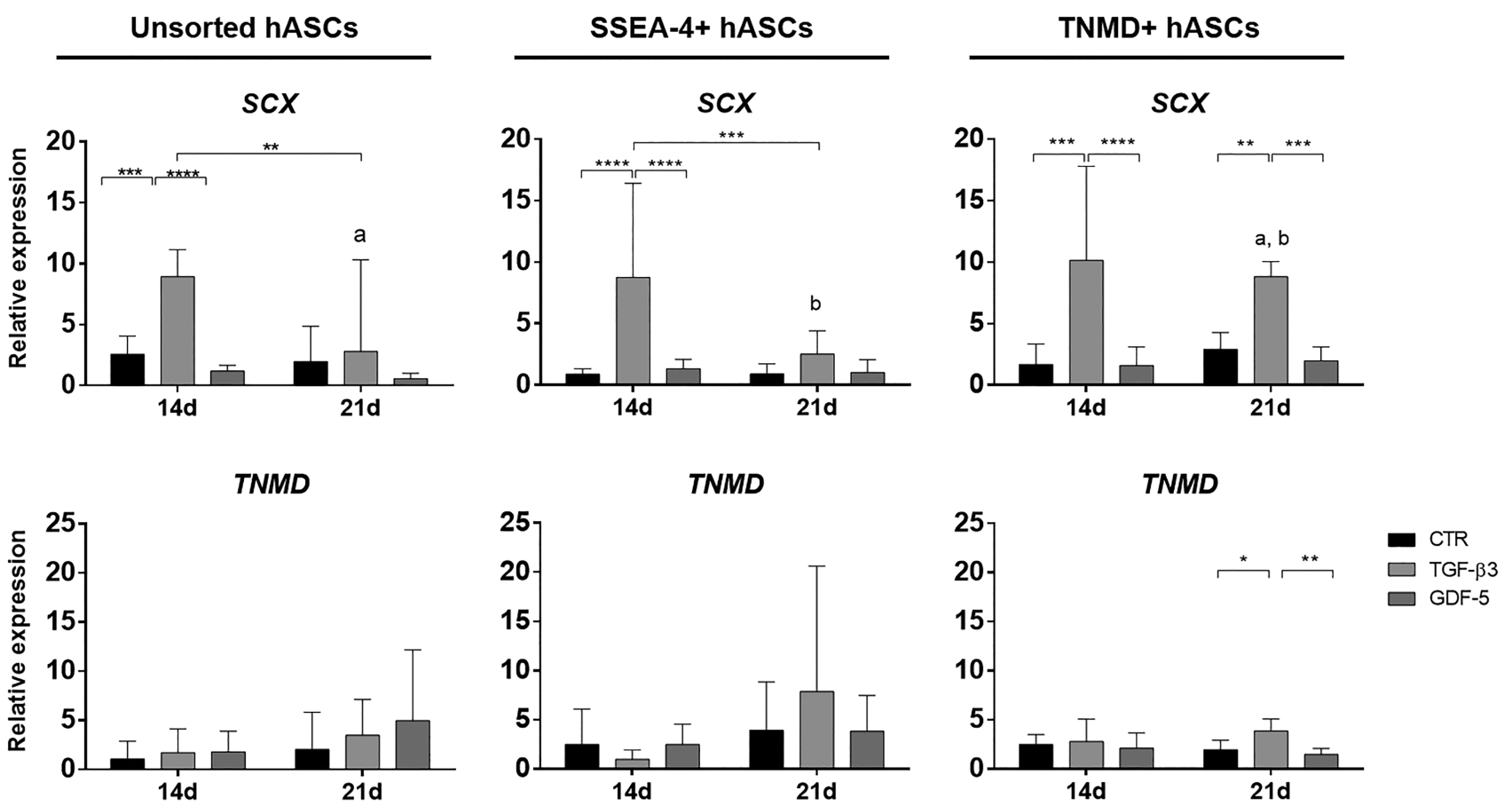

FIGURE 3 Gene expression of scleraxis (SCX) and tenomodulin (TNMD) in unsorted hASCs, SSEA-4-positive and TNMD-positive subpopulations cultured up to 21 days in basic medium (CTR), or media supplemented with TGF- $\beta 3$ or GDF-5. Gene expression levels were expressed relative to control conditions at day 7 in unsorted hASCs (control conditions). Data represent the mean \pm SD; ${ }^{*} p<.05,{ }^{* *} p<.01,{ }^{* * *} p<.001,{ }^{* * * *} p<.0001$

FIGURE 4 Western blot analysis of scleraxis expression in unsorted hASCs, SSEA-4+ hASCs and TNMD+ hASCs cultured for 14 days in basic medium (CTR), or media supplemented with TGF- $\beta 3$ or GDF-5. $\beta$-actin was used as loading control

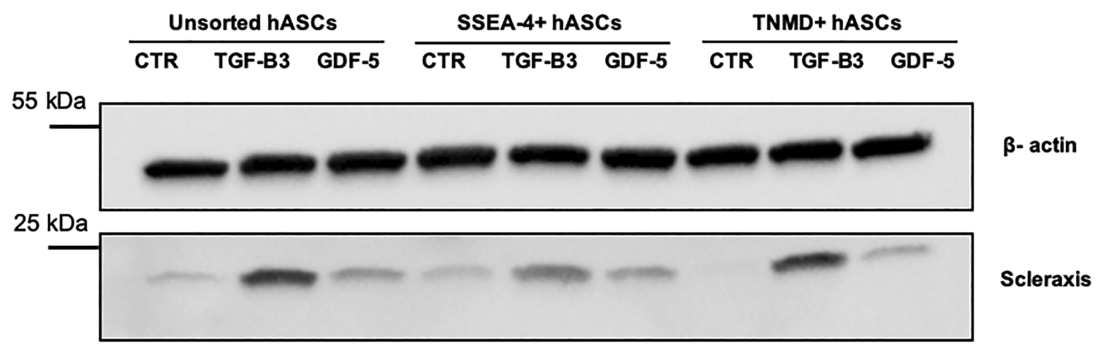

Although the expression of the tenogenic and ECM genes analyzed does not clearly identify a tenogenic prone profile among hASCs populations, the protein deposition clearly shows that ECM molecules are influenced by the growth factor supplementation and that unsorted and subpopulations of hASCs respond differently to the culture medium conditions.

Both hASCs subpopulations express high levels of COL3 and TNC in basal medium conditions in comparison with the unsorted hASCs. In TNMD+ hASCs in particular, the COL3 and TNC increases in GDF-5 supplemented cultures. Several reports have indicated GDF-5 contribution to a variety of musculoskeletal processes, including normal appendicular skeleton development and joint formation, tendon maintenance and healing post injury (Francis-West et al., 1999; Mikic, Schalet, Clark, Gaschen, \& Hunziker, 2001; Chhabra et al., 2003). GDF-5 treatment was also reported to enhance ECM deposition and up-regulate gene expression of tendon related markers in bone marrow and adipose tissue- derived MSCs, indicating their tenogenic commitment (Farng, Urdaneta, Barba, Esmende, \& McAllister, 2008; James et al., 2011; Park et al., 2010; Tan et al., 2012; Vuornos et al., 2016). In this work, a lower GDF-5 concentration $(50 \mathrm{ng} / \mathrm{ml}$ in comparison with the $100 \mathrm{ng} / \mathrm{ml}$ typically reported) was investigated. The selection of the GDF-5 concentration for this study was motivated by a study by Vuornos et al. (Vuornos et al., 2016) who successfully employed a $50 \mathrm{ng} / \mathrm{ml}$ dose and to several reports demonstrating that high concentrations of GDF-5 down-regulated expression of tendon markers in vitro and may contribute to formation of cartilaginous tissue in vivo (Dines et al., 2007).

Cell-based approaches shall regard the extent of the expression of tendon ECM components identified as beneficial for tendon repair. In this context, cell population selected for this study respond to the cell culture conditions investigated. However, the cell subsets investigated seem to play a more prominent role than the growth factor supplementation especially at the protein level.

Overall, GFs seem to play a role in the synthesis and deposition of ECM molecules present in tendon tissues, stimulating the hASCs subsets in different ways. The production of collagens, especially COL3 by unsorted hASCs is influenced by TGF- $\beta 3$, while SSEA-4+ hASCs do not require exogenous growth factors to produce COL3 
(a)

\section{Unsorted hASCs}

COL1A1

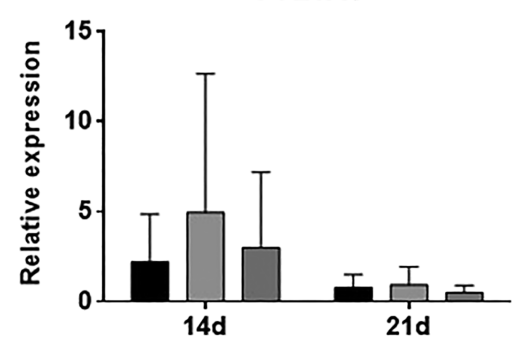

COL3A1

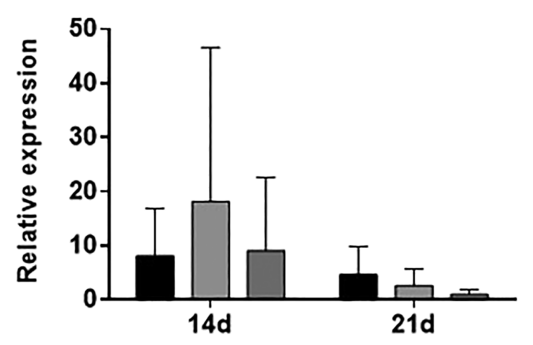

(b)

$D C N$

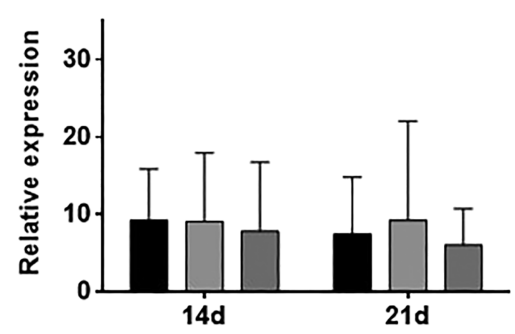

TNC

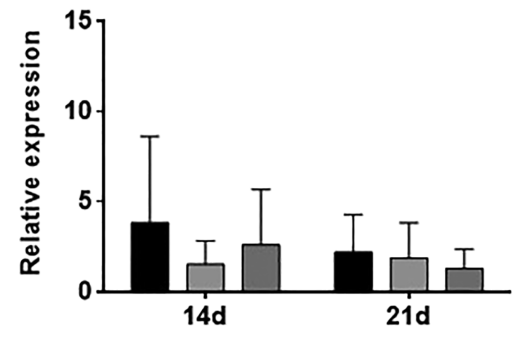

SSEA-4+ hASCs

TNMD+ hASCs

COL1A1

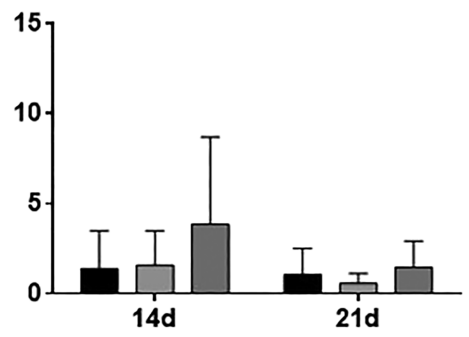

COL3A1

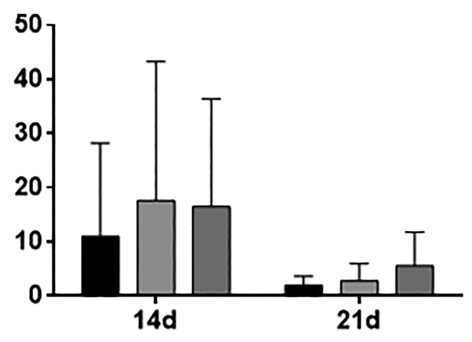

$D C N$

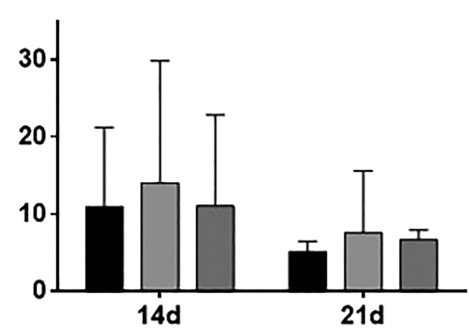

TNC

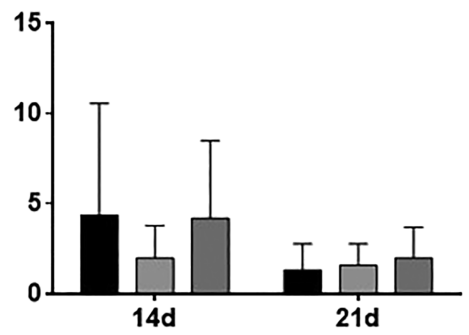

COL1A1

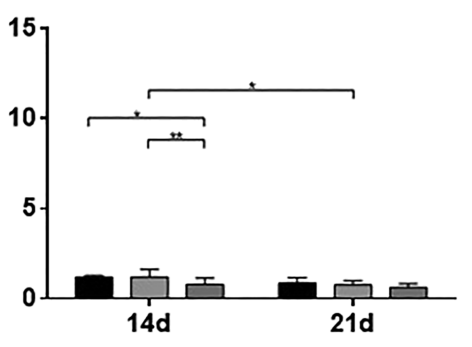

COL3A1

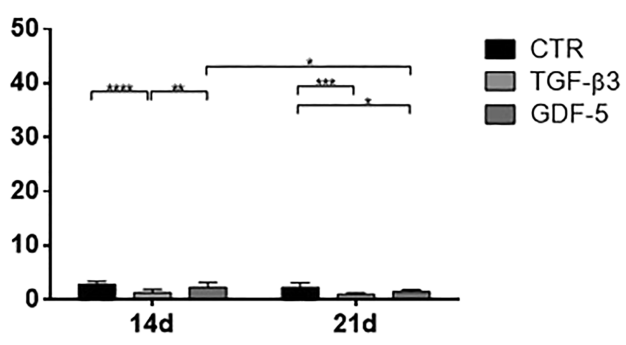

$D C N$

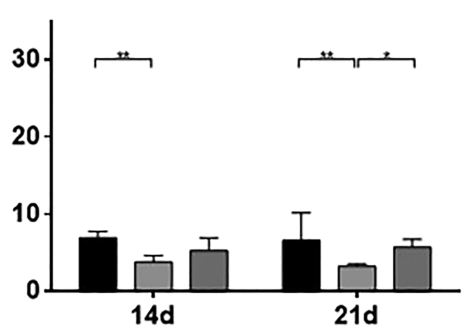

TNC

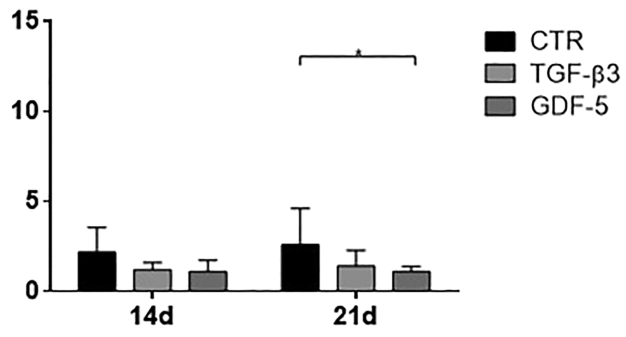

FIGURE 5 Gene expression of tendon ECM proteins: collagen type I (COL1A1), collagen type III (COL3A1), decorin (DCN) and tenascin C (TNC) in unsorted hASCs, SSEA-4-positive and TNMD-positive subpopulations cultured up to 21 days in basic medium (CTR) or media supplemented with TGF- $\beta 3$ or GDF-5. Gene expression levels were expressed relative to control conditions at day 7 in unsorted hASCs. Data represent the mean $\pm \mathrm{SD} ;{ }^{*} p<.05,{ }^{* *} p<.01,{ }^{* * *} p<.001,{ }^{* * * *} p<.0001$

and TNC rich matrix. Higher amounts of COL3 are produced in TNMD+ hASCs independently of the growth factors supplemented to the culture medium but the presence of GDF-5 in the culture medium of TNMD+ cells improves the synthesis of TNC. The fact that TNC is also present at enthesis also suggests a potential application of hASCs subsets in the establishment of cell-matrix interactions for interfacial strategies.
Even though some limitations exist regarding the efficiency of immunomagnetic sorting, this technology raises the possibility of using cell subsets more prone to acquire lineage specific characteristics, maximizing their differentiation capacity as opposed to the entire hASCs population. This is of major relevance to further advancing the recreation of a microenvironment that potentiates tendon regeneration and this work is a step forward in that direction. 
Collagen I
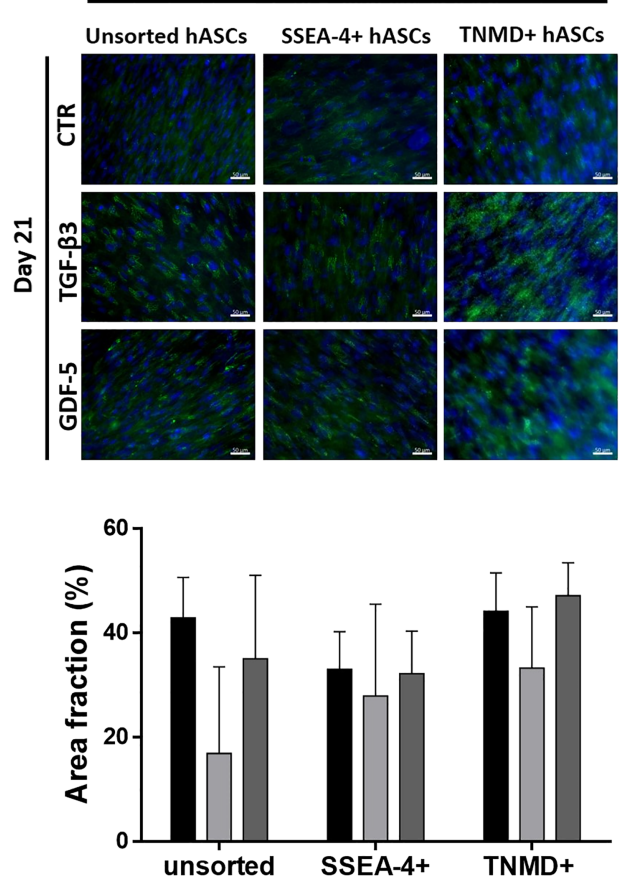

Collagen III
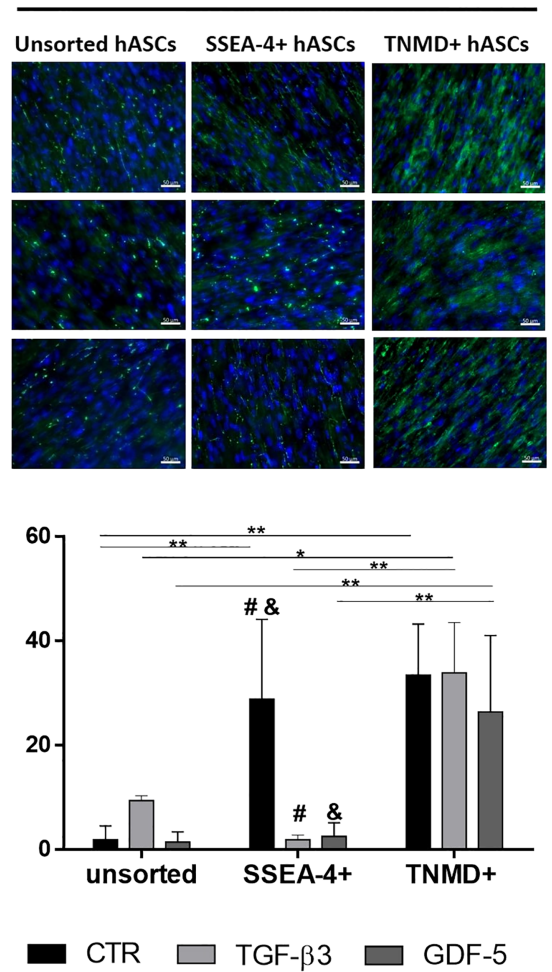

Tenascin C
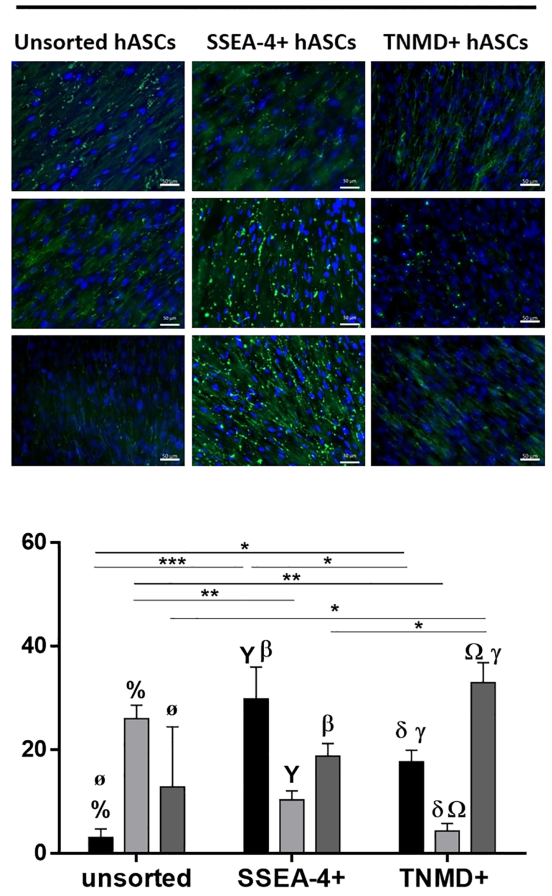

FIGURE 6 Evaluation of tendon ECM protein deposition and semi-quantification: collagen type I, collagen type III and tenascin C in unsorted hASCs, SSEA-4 hASCs and TNMD+ hASCs cultured for 21 days in basic medium (CTR) or media supplemented with TGF- $\beta 3$ or GDF- 5 . Collagen I, collagen III and tenascin C were stained in green. Nuclei were counterstained with DAPI. Scale bar represents $50 \mu \mathrm{m}$. Data represent the mean \pm SD; Statistical relevance between different cell populations is denoted as ${ }^{*} p<.05,{ }^{* *} p<.01,{ }^{* * *} p<.001,{ }^{* * *} p<.0001$ and differences observed between culture conditions within a cell population are indicated as $\varnothing, \delta, \gamma, \beta: p<.05, \#, \mathcal{\&}, \%, \gamma: p<.01, \Omega: p<.001$ [Colour figure can be viewed at wileyonlinelibrary.com]

\section{I CONCLUSION}

Identification of antigenically-defined subpopulations prone to differentiation towards specific cell lineages represents an attractive strategy to increase the effectiveness of cell-based therapies for musculoskeletal tissue engineering. In this study both SSEA-4+ hASCs and TNMD+ hASCs subsets produced increased amounts of tendon ECM proteins, namely collagen III and TNC in basal cultures in comparison with the crude hASCs. In particular, TNMD+ cells were found to be more susceptible to TGF- $\beta 3$ conditioning at the gene level although GDF-5 also seems to play a role in the production of tendon ECM proteins by TNMD+ hASCs. The differential response of hASCs subsets to microenvironmental stimuli anticipates intrincated mechanisms where cell subpopulations likely have dedicated roles to be further unveiled. Thus, the complexity of biological responses might require a combinatorial approach to guide stem cells commitment towards tendon-like phenotype anticipating improved regenerative strategies for tendon tissues.

\section{ACKNOWLEDGMENTS}

The authors would like to acknowledge Plastic Surgery Department of Hospital da Prelada (Porto, Portugal) for providing lipoaspirate samples.
The authors acknowledge the financial support from the European Union Framework Programme for Research and Innovation HORIZON 2020, under the Tendon Therapy Train Marie Skłodowska-Curie Innovative Training Network grant agreement No. 676338, the TEAMING Grant agreement No 739572 - The Discoveries CTR, and the Achilles Twinning Project No. 810850. Authors acknowledge also the European Research Council CoG MagTendon No. 772817, the FCT (Fundação para a Ciência e a Tecnologia) Project MagTT PTDC/CTMCTM/29930/2017 (POCl-01-0145-FEDER-29930), and the Project NORTE-01-0145-FEDER-000021: "Accelerating tissue engineering and personalized medicine discoveries by the integration of key enabling nanotechnologies, marine-derived biomaterials and stem cells", supported by Norte Portugal Regional Operational Programme (NORTE 2020), under the PORTUGAL 2020 Partnership Agreement, through the European Regional Development Fund (ERDF). ADE and $\mathrm{JdB}$ acknowledge the financial contribution of the Dutch province of Limburg in the LINK (FCL67723; "Limburg INvesteert in haar Kenniseconomie") knowledge economy project.

\section{CONFLICT OF INTEREST}

The authors declare no conflict of interest. 


\section{AUTHOR CONTRIBUTIONS}

DB, AIG, MTR, and MEG conceived and designed the experiments. $\mathrm{DB}, \mathrm{AIG}$ and ADE performed the experiments. DB, AIG, MTR, ADE, JdB, RLR and MEG analysed and interpreted the data. DB, AIG, MTR and MEG wrote the manuscript. All authors reviewed and approved the final manuscript.

\section{ORCID}

Ana I. Gonçalves (1) https://orcid.org/0000-0002-0466-9292

Dominika Berdecka (iD https://orcid.org/0000-0003-1035-2520

\section{REFERENCES}

Adewumi, O., Aflatoonian, B., Ahrlund-Richter, L., Amit, M., Andrews, P. W. Beighton, G., ... Zhang, W. (2007). Characterization of human embryonic stem cell lines by the International Stem Cell Initiative. Nature Biotechnology. https://doi.org/10.1038/nbt1318

Alberton, P., Dex, S., Popov, C., Shukunami, C., Schieker, M., \& Docheva, D. (2015). Loss of tenomodulin results in reduced self-renewal and augmented senescence of tendon stem/progenitor cells. Stem Cells and Development. https://doi.org/10.1089/scd.2014.0314

Barnes, M. J. (1975). Function of ascorbic acid in collagen metabolism. Annals of the New York Academy of Sciences. https://doi.org/10.1111/ j.1749-6632.1975.tb29287.x

Brandau, O., Meindl, A., Fässler, R., \& Aszódi, A. (2001). A novel gene, tendin, is strongly expressed in tendons and ligaments and shows high homology with chondromodulin-I. Developmental Dynamics, 221(1), 72-80. https://doi.org/10.1002/dvdy.1126

Brellier, F., Tucker, R. P., \& Chiquet-Ehrismann, R. (2009). Tenascins and their implications in diseases and tissue mechanics. Scandinavian Journal of Medicine \& Science in Sports, 19(4), 511-519. https://doi.org/ 10.1111/j.1600-0838.2009.00916.x

Burk, J., Gittel, C., Heller, S., Pfeiffer, B., Paebst, F., Ahrberg, A. B., \& Brehm, W. (2014). Gene expression of tendon markers in mesenchymal stromal cells derived from different sources. BMC Research Notes. https://doi. org/10.1186/1756-0500-7-826

Chen, S., \& Birk, D. E. (2013). The regulatory roles of small leucine-rich proteoglycans in extracellular matrix assembly. The FEBS Journal. https:// doi.org/10.1111/febs.12136

Chhabra, A., Tsou, D., Clark, R. T., Gaschen, V., Hunziker, E. B., \& Mikic, B. (2003). GDF-5 deficiency in mice delays Achilles tendon healing. Journal of Orthopaedic Research. https://doi.org/10.1016/S0736-0266(03) 00049-4

Chiquet-Ehrismann, R., \& Tucker, R. P. (2004). Connective tissues: Signalling by tenascins. The International Journal of Biochemistry \& Cell Biology. https://doi.org/10.1016/j.biocel.2004.01.007

Connizzo, B. K., Yannascoli, S. M., \& Soslowsky, L. J. (2013). Structure-function relationships of postnatal tendon developmeent: A parallel to healing. Matrix Biology, 32(2), 106-116.

Cserjesi, P., Brown, D., Ligon, K. L., Lyons, G. E., Copeland, N. G., Gilbert, D. J., ... Olson, E. N. (1995). Scleraxis: A basic helix-loop-helix protein that prefigures skeletal formation during mouse embryogenesis. Development.

Czubryt, M. P. (2012). Common threads in cardiac fibrosis, infarct scar formation. and wound healing. Fibrogenesis Tissue Repair, 5(1), 19. https:// doi.org/10.1186/1755-1536-5-19

De Mattos Carvalho, A., Alves, A. L. G., De Oliveira, P. G. G., Cisneros Álvarez, L. E., Amorim, R. L., Hussni, C. A., \& Deffune, E. (2011). Use of adipose tissue-derived mesenchymal stem cells for experimental tendinitis therapy in equines. Journal of Equine Veterinary Science. https://doi.org/10.1016/j.jevs.2010.11.014

Dines, J. S., Weber, L., Razzano, P., Prajapati, R., Timmer, M., Bowman, S., ... Grande, D. P. (2007). The effect of growth differentiation factor-5coated sutures on tendon repair in a rat model. Journal of Shoulder and Elbow Surgery. https://doi.org/10.1016/j.jse.2007.03.001

Docheva, D., Hunziker, E. B., Fassler, R., \& Brandau, O. (2005) Tenomodulin is necessary for tenocyte proliferation and tendon maturation. Molecular and Cellular Biology. https://doi.org/10.1128/ MCB.25.2.699-705.2005

Farng, E., Urdaneta, A. R., Barba, D., Esmende, S., \& McAllister, D. R. (2008). The effects of GDF-5 and uniaxial strain on mesenchymal stem cells in 3-D culture. Clinical Orthopaedics and Related Research. https://doi.org/ 10.1007/s11999-008-0300-x

Francis-West, P. H., Abdelfattah, A., Chen, P., Allen, C., Parish, J., Ladher, R., ... Archer, C. W. (1999). Mechanisms of GDF-5 action during skeletal development. Development (Cambridge, England).

Frese, L., Dijkman, P. E., \& Hoerstrup, S. P. (2016). Adipose tissue-derived stem cells in regenerative medicine. Transfusion Medicine and Hemotherapy. https://doi.org/10.1159/000448180

Gimble, J. M., Bunnell, B. A., \& Guilak, F. (2012). Human adipose-derived cells: An update on the transition to clinical translation. Regenerative Medicine. https://doi.org/10.2217/rme.11.119

Gonçalves, A. I., Gershovich, P. M., Rodrigues, M. T., Reis, R. L., \& Gomes, M. E. (2018). Human adipose tissue-derived tenomodulin positive subpopulation of stem cells: A promising source of tendon progenitor cells. Journal of Tissue Engineering and Regenerative Medicine. https://doi.org/ 10.1002/term.2495

Guilak, F., Lott, K. E., Awad, H. A., Cao, Q., Hicok, K. C., Fermor, B., \& Gimble, J. M. (2006). Clonal analysis of the differentiation potential of human adipose-derived adult stem cells. Journal of Cellular Physiology, 206(1), 229-237. https://doi.org/10.1002/jcp.20463

Handgretinger, R., Klingebiel, T., Lang, P., Schumm, M., Neu, S., Geiselhart, A., ... Niethammer, D. (2001). Megadose transplantation of purified peripheral blood CD34+progenitor cells from HLA-mismatched parental donors in children. Bone Marrow Transplantation, 27(8), 777-783. https://doi.org/10.1038/sj.bmt.1702996

Hao, J., Varshney, R. R., \& Wang, D. A. (2008). TGF-beta3: A promising growth factor in engineered organogenesis. Expert Opinion on Biological Therapy, 8(10), 1485-1493. https://doi.org/10.1517/ 14712598.8.10.1485

Henry, T. D., Schaer, G. L., Traverse, J. H., Povsic, T. J., Davidson, C., Lee, J. S., ... Losordo, D. W. (2016). Autologous CD34 ${ }^{+}$cell therapy for refractory angina: 2-year outcomes from the ACT34-CMI study. Cell Transplantation, 25(9), 1701-1711. https://doi.org/10.3727/ $096368916 \times 691484$

Hou, Y., Ni, M., Lin, S., Sun, Y., Lin, W., Liu, Y., ... Xu, L. (2017). Tenomodulin highly expressing MSCs as a better cell source for tendon injury healing. Oncotarget. https://doi.org/10.18632/oncotarget.20495

James, R., Kumbar, S. G., Laurencin, C. T., Balian, G., \& Chhabra, A. B. (2011). Tendon tissue engineering: Adipose-derived stem cell and GDF-5 mediated regeneration using electrospun matrix systems. Biomedical Materials. https://doi.org/10.1088/1748-6041/6/2/025011

Jiang, K., Chun, G., Wang, Z., Du, Q., Wang, A., \& Xiong, Y. (2016). Effect of transforming growth factor-beta3 on the expression of Smad3 and Smad7 in tenocytes. Molecular Medicine Reports, 13(4), 3567-3573. https://doi.org/10.3892/mmr.2016.4944

Jiang, Y., Shi, Y., He, J., Zhang, Z., Zhou, G., Zhang, W., ... Liu, W. (2017). Enhanced tenogenic differentiation and tendon-like tissue formation by tenomodulin overexpression in murine mesenchymal stem cells. 
Journal of Tissue Engineering and Regenerative Medicine. https://doi.org/ 10.1002/term. 2150

Johal, K. S., Lees, V. C., \& Reid, A. J. (2015). Adipose-derived stem cells: Selecting for translational success. Regenerative Medicine. https://doi. org/10.2217/rme.14.72

Jurgens, W. J. F. M., Oedayrajsingh-Varma, M. J., Helder, M. N., ZandiehDoulabi, B., Schouten, T. E., Kuik, D. J., ... Van Milligen, F. J. (2008). Effect of tissue-harvesting site on yield of stem cells derived from adipose tissue: Implications for cell-based therapies. Cell and Tissue Research, 332(3), 415-426. https://doi.org/10.1007/s00441-0070555-7

Kimura, N., Shukunami, C., Hakuno, D., Yoshioka, M., Miura, S., Docheva, D., ... Fukuda, K. (2008). Local tenomodulin absence, angiogenesis, and matrix metalloproteinase activation are associated with the rupture of the chordae tendineae cordis. Circulation. https://doi.org/10.1161/ CIRCULATIONAHA.108.780031

Leung, M., Jana, S., Tsao, C. T., \& Zhang, M. (2013). Tenogenic differentiation of human bone marrow stem cells via a combinatory effect of aligned chitosan-poly-caprolactone nanofibers and TGF- $\beta 3$. Journal of Materials Chemistry B. https://doi.org/10.1039/c3tb20825g

Liu, H., Zhang, C., Zhu, S., Lu, P., Zhu, T., Gong, X., ... Ouyang, H. W. (2014). Mohawk promotes the tenogenesis of mesenchymal stem cells through activation of the TGF $\beta$ signaling pathway. Stem Cells (Dayton, Ohio), 33(2), 443-455. https://doi.org/10.1002/stem.1866

Livak, K. J., \& Schmittgen, T. D. (2001). Analysis of relative gene expression data using real-time quantitative PCR and the 2-delta-delta-CT Method. Methods, 25, 402-408. https://doi.org/10.1006/ meth.2001.1262

Lv, F.-J., Tuan, R. S., Cheung, K. M. C., \& Leung, V. Y. L. (2014). Concise review: The surface markers and identity of human mesenchymal stem cells. Stem Cells. https://doi.org/10.1002/stem.1681

Manning, C. N., Kim, H. M., Sakiyama-Elbert, S., Galatz, L. M., Havlioglu, N., $\&$ Thomopoulos, S. (2011). Sustained delivery of transforming growth factor beta three enhances tendon-to-bone healing in a rat model. Journal of Orthopaedic Research. https://doi.org/10.1002/jor.21301

McLeod, C. M., \& Mauck, R. L. (2017). On the origin and impact of mesenchymal stem cell heterogeneity: New insights and emerging tools for single cell analysis. European Cells \& Materials, 34, 217-231. https:// doi.org/10.22203/eCM.v034a14

Mihaila, S. M., Frias, A. M., Pirraco, R. P., Rada, T., Reis, R. L., Gomes, M. E., \& Marques, A. P. (2013). Human adipose tissue-derived SSEA-4 subpopulation multi-differentiation potential towards the endothelial and osteogenic lineages. Tissue Engineering. Part A, 19(1-2), 235-246. https://doi.org/10.1089/ten.TEA.2012.0092

Mikic, B., Schalet, B. J., Clark, R. T., Gaschen, V., \& Hunziker, E. B. (2001). GDF-5 deficiency in mice alters the ultrastructure, mechanical properties and composition of the Achilles tendon. Journal of Orthopaedic Research. https://doi.org/10.1016/S0736-0266(00)90018-4

Mitchell, J. B., McIntosh, K., Zvonic, S., Garrett, S., Floyd, Z. E., Kloster, A., ... Gimble, J. M. (2006). Immunophenotype of human adipose-derived cells: Temporal changes in stromal-associated and stem cellassociated markers. Stem Cells. https://doi.org/10.1634/ stemcells.2005-0234

Mo, M., Wang, S., Zhou, Y., Li, H., \& Wu, Y. (2016). Mesenchymal stem cell subpopulations: Phenotype, property and therapeutic potential. Cellular and Molecular Life Sciences. https://doi.org/10.1007/s00018-0162229-7

Nakamura, N., Hart, D. A., Boorman, R. S., Kaneda, Y., Shrive, N. G., Marchuk, L. L., ... Frank, C. B. (2000). Decorin antisense gene therapy improves functional healing of early rabbit ligament scar with enhanced collagen fibrillogenesis in vivo. Journal of Orthopaedic Research. https:// doi.org/10.1002/jor.1100180402

Oshima, Y., Shukunami, C., Honda, J., Nishida, K., Tashiro, F., Miyazaki, J. I., ... Tano, Y. (2003). Expression and localization of tenomodulin, a transmembrane type chondromodulin-I-related angiogenesis inhibitor, in mouse eyes. Investigative Ophthalmology and Visual Science, 44(5), 1814-1823. https://doi.org/10.1167/iovs.02-0664

Park, A., Hogan, M. V., Kesturu, G. S., James, R., Balian, G., \& Chhabra, A. B. (2010). Adipose-derived mesenchymal stem cells treated with growth differentiation factor-5 express tendon-specific markers. Tissue Engineering Parts A. https://doi.org/10.1089/ten.tea.2009.0710

Pérez-Silos, V., Camacho-Morales, A., \& Fuentes-Mera, L. (2016). Mesenchymal stem cells subpopulations: Application for orthopedic regenerative medicine. Stem Cells International. https://doi.org/ 10.1155/2016/3187491

Perucca Orfei, C., Vigano, M., Pearson, J. R., Colombini, A., De Luca, P., Ragni, E., ... de Girolamo, L. (2019). In vitro induction of tendonspecific markers in tendon cells, adipose- and bone marrow-derived stem cells is dependent on TGFbeta3, BMP-12 and ascorbic acid stimulation. International Journal of Molecular Sciences, 20(1). https://doi. org/10.3390/ijms20010149

Pryce, B. A., Watson, S. S., Murchison, N. D., Staverosky, J. A., Dunker, N., \& Schweitzer, R. (2009). Recruitment and maintenance of tendon progenitors by TGF signaling are essential for tendon formation. Development. https://doi.org/10.1242/dev.027342

Qi, J., Dmochowski, J. M., Banes, A. N., Tsuzaki, M., Bynum, D., Patterson, M., ... Banes, A. J. (2012). Differential expression and cellular localization of novel isoforms of the tendon biomarker tenomodulin. Journal of Applied Physiology (Bethesda, MD: 1985), 113(6), 861-871. https:// doi.org/10.1152/japplphysiol.00198.2012

Rada, T., Gomes, M. E., \& Reis, R. L. (2011). A novel method for the isolation of subpopulations of rat adipose stem cells with different proliferation and osteogenic differentiation potentials. Journal of Tissue Engineering and Regenerative Medicine. https://doi.org/10.1002/ term.364

Saiki, A., Olsson, M., Jernås, M., Gummesson, A., McTernan, P. G., Andersson, J., ... Carlsson, L. M. S. (2009). Tenomodulin is highly expressed in adipose tissue, increased in obesity, and down-regulated during diet-induced weight loss. The Journal of Clinical Endocrinology and Metabolism. https://doi.org/10.1210/jc.2009-0292

Schaefer, L., \& Schaefer, R. M. (2010). Proteoglycans: From structural compounds to signaling molecules. Cell and Tissue Research. https://doi.org/ 10.1007/s00441-009-0821-y

Schneider, M., Angele, P., Järvinen, T. A. H., \& Docheva, D. (2017). Rescue plan for. Achilles: Therapeutics steering the fate and functions of stem cells in tendon wound healing. Advanced Drug Delivery Reviews. https://doi.org/10.1016/j.addr.2017.12.016

Sharma, P., \& Maffulli, N. (2006). Biology of tendon injury: Healing, modeling and remodeling. Journal of Musculoskeletal \& Neuronal Interactions. https://doi.org/10.1016/j.math.2014.02.002

Shevinsky, L. H., Knowles, B. B., Damjanov, I., \& Solter, D. (1982). Monoclonal antibody to murine embryos defines a stage-specific embryonic antigen expressed on mouse embryos and human teratocarcinoma cells. Cell. https://doi.org/10.1016/0092-8674(82)90274-4

Shukunami, C., Oshima, Y., \& Hiraki, Y. (2001). Molecular cloning of tenomodulin, a novel Chondromodulin-I related gene. Biochemical and Biophysical Research Communications, 280(5), 1323-1327. https://doi. org/10.1006/bbrc.2001.4271

Tan, S.-L., Ahmad, R. E., Ahmad, T. S., Merican, A. M., Abbas, A. A., Ng, W. M., \& Kamarul, T. (2012). Effect of growth differentiation factor 5 on the proliferation and tenogenic differentiation potential of human 
mesenchymal stem cells in vitro. Cells, Tissues, Organs. https://doi.org/ $10.1159 / 000335693$

Taylor, S. E., Vaughan-Thomas, A., Clements, D. N., Pinchbeck, G., MacRory, L. C., Smith, R. K., \& Clegg, P. D. (2009). Gene expression markers of tendon fibroblasts in normal and diseased tissue compared to monolayer and three dimensional culture systems. BMC Musculoskeletal Disorders, 10(27). https://doi.org/10.1186/1471-2474-10-27

Thomson, J. A. (1998). Embryonic stem cell lines derived from human blastocysts. Science. https://doi.org/10.1126/science.282.5391.1145

Uysal, C. A., Tobita, M., Hyakusoku, H., \& Mizuno, H. (2012). Adiposederived stem cells enhance primary tendon repair: Biomechanical and immunohistochemical evaluation. Journal of Plastic, Reconstructive \& Aesthetic Surgery. https://doi.org/10.1016/j.bjps.2012.06.011

Vuornos, K., Björninen, M., Talvitie, E., Paakinaho, K., Kellomäki, M. Huhtala, H., ... Haimi, S. (2016). Human adipose stem cells differentiated on braided polylactide scaffolds is a potential approach for tendon tissue engineering. Tissue Engineering Parts A. https://doi.org/ 10.1089/ten.tea.2015.0276

Wagner, W., Wein, F., Seckinger, A., Frankhauser, M., Wirkner, U., Krause, U., ... Ho, A. D. (2005). Comparative characteristics of mesenchymal stem cells from human bone marrow, adipose tissue, and umbilical cord blood. Experimental Hematology, 33(11), 1402-1416. https://doi.org/ 10.1016/j.exphem.2005.07.003

Wang, J. H. C. (2006). Mechanobiology of tendon. Journal of Biomechanics. https://doi.org/10.1016/j.jbiomech.2005.05.011

Wolfman, N. M., Hattersley, G., Cox, K., Celeste, A. J., Nelson, R., Yamaji, N., ... Rosen, V. (1997). Ectopic induction of tendon and ligament in rats by growth and differentiation factors 5,6 , and 7 , members of the TGF- $\beta$ gene family. The Journal of Clinical Investigation. https://doi.org/ 10.1172/JCl119537

Yamana, K., Wada, H., Takahashi, Y., Sato, H., Kasahara, Y., \& Kiyoki, M. (2001). Molecular cloning and characterization of ChM1L, a novel membrane molecule similar to chondromodulin-I. Biochemical and Biophysical Research Communications. https://doi.org/10.1006/ bbrc. 2000.4245

Zhu, M., Heydarkhan-Hagvall, S., Hedrick, M., Benhaim, P., \& Zuk, P. (2013). Manual isolation of adipose-derived stem cells from human lipoaspirates. Journal of Visualized Experiments, (79). https://doi.org/ $10.3791 / 50585$

Zuk, P. (2001). a, Zhu, M., Mizuno, H., Huang, J., Futrell, J. W., Katz, a J., ... Hedrick, M. H. Multilineage cells from human adipose tissue: Implications for cell-based therapies. Tissue Engineering. https://doi.org/ 10.1089/107632701300062859

Zuk, P. A., Zhu, M., Ashjian, P., De Ugarte, D. A., Huang, J. I., Mizuno, H., ... Hedrick, M. H. (2002). Human adipose tissue is a source of multipotent stem cells. Molecular Biology of the Cell. https://doi.org/10.1091/mbc. E02

How to cite this article: Gonçalves Al, Berdecka D, Rodrigues MT, et al. Evaluation of tenogenic differentiation potential of selected subpopulations of human adipose-derived stem cells. J Tissue Eng Regen Med. 2019;1-14. https://doi.org/10.1002/ term.2967 